\title{
DETECTION OF SEEPAGE SLICKS IN CANTARELL COMPLEX (GULF OF MEXICO) USING POLARIMETRIC SAR DATA OF RADARSAT-2
}

\author{
Sarah Barrón Torres ${ }^{1}$, Luiz Bevilacqua ${ }^{2}$, Fernando Pellon de Miranda ${ }^{3}$ and Carlos Henrique Beis $\left.\right|^{3}$
}

\begin{abstract}
The occurrence of oil seeps on the sea surface from active petroleum systems has been extensively documented by radar imaging using SAR (Synthetic Aperture Radar). Polarimetry is consolidating in the oil industry as a sophisticated technique for the study of marine seeps. The Cantarell Complex, located in the Gulf of Mexico, is currently the most prolific natural seep site in the world. This paper aims to add to the discussion on the physical properties of seepage slicks from full polarimetric data (quad-pol) from RADARSAT-2 satellite. The fact that the research was based on two images (ID\#02 and ID\#04) acquired at the same place and with the same mode of operation but with a time lapse between acquisitions and different incidence angles allowed to evaluate the influence of the imaging geometry on target signatures. To this end, samples of four classes (sea, offshore platform, oil and false targets) were collected. The data of the samples were afterwards shown in graphs and plotted in the classification plan of Cloude \& Pottier - entropy $(H)$ vs. alpha angle $(\bar{\alpha})$ - for backscattering mechanism analysis. Such elements made it possible to certify that (i) the sea is a Bragg type surface regardless the incidence angle, (ii) platforms have double-bounce scattering, but small incidence angles are inadequate for their characterization, (iii) false targets (associated in ID\#02 to regions of little wind) are moderately random/quasi deterministic surfaces, and (iv) oil behaves either as a Bragg (19.0 $-22.7^{\circ}$ incidence angle range) or as a random/anisotropic surface $\left(33.7^{\circ}-36.7^{\circ}\right.$ incidence angle range).
\end{abstract}

Keywords: $H-\bar{\alpha}$ diagram, incidence angle, radar imaging, marine seeps.

RESUMO. A ocorrência de exsudações de óleo na superfície do mar a partir de sistemas petroliferos ativos vem sendo extensivamente documentada por imageamento utilizando sistemas SAR (Synthetic Aperture Radar). A polarimetria está se consolidando na indústria do petróleo como uma técnica sofisticada para o estudo de seeps marinhos. 0 Complexo de Cantarell, situado no Golfo do México, é atualmente o local de exsudação natural de óleo mais prolífico do globo terrestre. Este trabalho visou contribuir com a discussão acerca das propriedades físicas de escapes de óleo a partir dos dados polarimétricos completos (quad-po) do satélite RADARSAT-2. 0 fato da pesquisa valer-se de duas imagens (ID\#02 e ID\#04) adquiridas no mesmo local e modo de operação, mas com intervalo entre as aquisições e diferentes ângulos de incidência, possibilitou avaliar a influência da geometria de imageamento na assinatura dos alvos. Com esse propósito, foram geradas amostras de quatro classes (mar, plataforma, óleo e falso alvo), que tiveram os dados posteriormente relacionados em gráficos e no plano de classificação de Cloude \& Pottier - entropia $(H)$ vs. ângulo alfa $(\bar{\alpha})$ - para análise do mecanismo de espalhamento. Tais elementos permitiram atestar que (i) o mar é uma superfície do tipo Bragg independente do ângulo de incidência, (ii) as plataformas têm espalhamento double-bounce, mas baixos ângulos são inadequados para sua caracterização, (iii) falsos alvos (associados em ID\#02 a regiões de baixo vento) são superfícies moderadamente aleatórias/quase determinísticas, e (iv) o óleo comporta-se ou como Bragg $\left(19,0^{\circ}-22,7^{\circ}\right)$, ou como uma superfície aleatória/anisotrópica $\left(33,7^{\circ}-36,7^{\circ}\right)$.

Palavras-chave: diagrama $H$ - $\bar{\alpha}$, ângulo de incidência, imagem de radar, seeps marinhos.

\footnotetext{
1 Universidade Federal do Rio de Janeiro, Laboratório de Sensoriamento Remoto por Radar Aplicado à Indústria do Petróleo, LabSAR, Centro de Tecnologia, Bloco I, sala I-114, Cidade Universitária, 21941-972 Rio de Janeiro, RJ, Brazil. Phone: +55(21) 3938-8433/99922-4504 - E-mail: sarah.barron89@gmail.com

2 Universidade Federal do Rio de Janeiro, Instituto Alberto Luiz Coimbra de Pós-Graduação e Pesquisa de Engenharia, COPPE, Centro de Tecnologia, Bloco B, sala 101, Cidade Universitária, 21945-970 Rio de Janeiro, RJ, Brazil. Phone: +55(21)2562-8461 - E-mail: bevilacqua@coc.ufrj.br

3 Universidade Federal do Rio de Janeiro, Laboratório de Sensoriamento Remoto por Radar Aplicado à Indústria do Petróleo, LabSAR, Centro de Tecnologia, Bloco I, sala I-114, Cidade Universitária, 21941-972 Rio de Janeiro, RJ, Brazil. Phone: +55(21) 3938-8433 - E-mails: pellon@labsar.coppe.ufrj.br; beis|@labsar.coppe.ufr..br
} 


\section{INTRODUCTION}

The oil industry is in growing activity, still being considered the major source of primary energy in most parts of the world (IEA, 2015). Multidisciplinary scientific development promotes the reduction of exploratory risks, reducing the companies' costs and making the operation capable of ensuring the return of investments in the long term. The occurrence of oil on the sea surface infers two alternatives, either leakage from active petroleum systems resulting in features usually called seepage slicks, or spills (including accidents in platforms and operation problems among others).

The acknowledged existence of natural oil seep in the Gulf of Mexico makes the region of great economic and environmental interest. Mexico is the tenth largest oil exporter in the world (IEA, 2015). The Cantarell Complex, located in the Bay of Campeche, is currently the most prolific natural seep site in the world. Remote sensing is an essential tool in this exploratory scenario.

Synthetic Aperture Radar (SAR) orbital systems have stood out in the survey and monitoring of natural resources. Some of their most important attributes are the independence of solar illumination, little influence of the atmosphere during imaging (Migliaccio et al., 2012) and the detection of responses indicatives of the targets' electrical and geometrical properties. Polarimetric SAR systems allow full characterization (quad-pol) of the electromagnetic wave from the targets, because they register the signature of the object scattering on the surface, keeping the measures of amplitude and phase collected at the reception (Zhang et al., 2011).

The purpose of this research was to aid, using polarimetric images, in the recognition and characterization of sea surface slicks. From the precepts of the literature, an analysis was found, based on the classification by Cloude \& Pottier (1997), in accordance with their theory of decomposition of scattering mechanisms, that confronts the parameters entropy $(H)$ and alpha angle $(\bar{\alpha})$ in a simple diagram divided into nine different zones. In this respect, Tian et al. (2010), Zhang et al. (2011), Staples \& Touzi (2014) and Skrunes et al. (2014), using $H, \bar{\alpha}$ and, sometimes a third parameter, anisotropy $(A)$, could discriminate oilfree portions of the sea surface from areas covered by oil.

The objective of this paper is to describe the physical properties of the oil seeps in the Cantarell Complex to distinguish them from the surrounding medium, from information available in RADARSAT-2 satellite data obtained by SAR sensor. It also aim at (i) assessing the performance of the polarimetric classification technique based on Cloude \& Pottier scattering mechanism decomposition theory (1997); (ii) comparing the results with values in the literature and selecting the parameters that better describe the targets of interest; and (iii) analyzing the influence of the imaging geometry (changes in the incidence angle and look azimuth) on the polarimetric signature of oil scattering on the sea surface.

\section{STUDY AREA}

It is $134 \mathrm{~km}^{2}$ oil region that comprises several exploration fields (CNH, 2013), corresponding to the Cantarell Complex, located approximately $80 \mathrm{~km}$ northeast from Ciudad del Carmen, in the Bay of Campeche, inserted in the Mexican portion of the Gulf of Mexico (Fig. 1).

Cantarell was discovered in 1976 and its exploitation was conducted until recently as a monopoly of state-owned PEMEX (Petróleos Mexicanos). In 2004, the production volume of the Complex represented about $59 \%$ of the national total (PEMEX, 2005), when Mexico achieved record production, but from then on there was a decline. In any case, Cantarell remains one of the world's greatest oil provinces, and the maintenance of the natural oil seep attracts both, economic and scientific interest.

\section{GEOLOGIC CONTEXT}

The stratigraphy of the Campeche Sound, in the Bay of Campeche, where the Cantarell Complex occurs, is formed mainly by carbonates and marine terrigens from Jurassic to Cenozoic ages, which cover older Jurassic evaporitic sequences at its base.

The oil is stored mainly in a carbonate breccia in the Cretaceous-Tertiary (K/T) boundary in structural trapping with a thickness of up to $300 \mathrm{~m}$ (Ibarra, 2009). The density of this essentially heavy oil varies from 10 to $25^{\circ} \mathrm{APl}$; which is believed to be due to the early expulsion from the source rock and not to biodegradation.

The tectonic evolution comprises three major events that define four structural styles, which are, from the oldest to the most recent, originated by: (i) extension efforts, (ii) compression efforts, (iii) transpressive efforts and (iv) late extension event (Flores Ibarra et al., 2013).

\section{Theoretical Revision}

Performing a polarimetric SAR data decomposition involves obtaining information on the scattering mechanism, allowing to separate the different contributions of the interaction process with the target of the incident electromagnetic pulse (ESA, 2015). The technique of Cloude \& Pottier (1997) is among the most cited in the literature for application when the targets of interest 


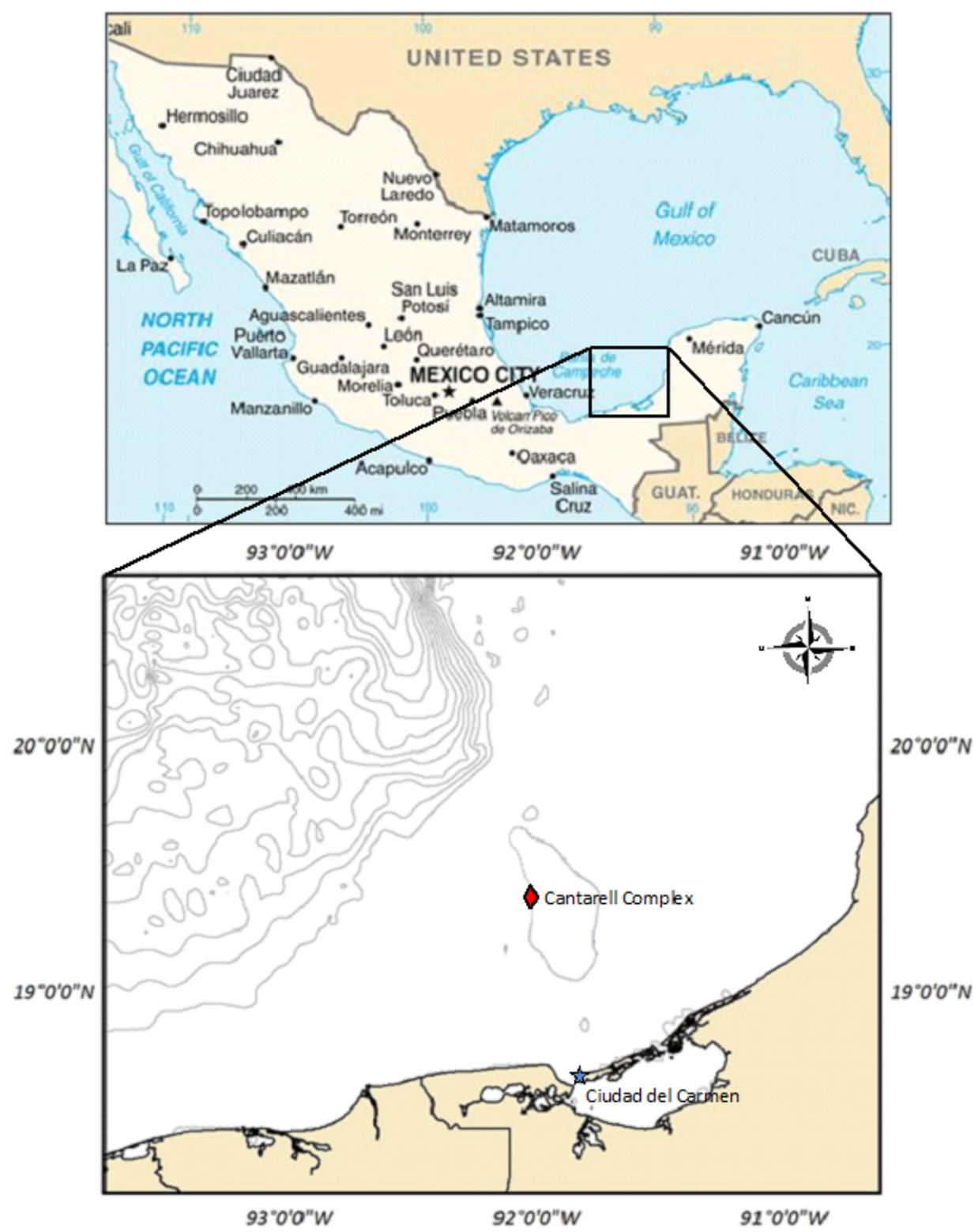

Figure 1 - Localization map of the study area (Source: Power Engineering, 2015). The red lozenge represents the Cantarell Complex.

are non-deterministic (or extensive), i.e., targets with dimensions significantly larger that the area of illumination of the radar beam.

The oil slicks studied, as well as other features of the real world, are included in this type, because they are scattered in dynamics environments and subject to changes in space and time. In the present study, the aforementioned model was used in the analysis of polarimetric data (quad-pol) from RADARSAT-2.

The theory of decomposition by eigenvalues and eigenvectors of the coherency matrix (T3) of Cloude \& Pottier (1997) three parameters are used to facilitate polarimetric SAR data analysis (Lee \& Pottier, 2009):
- Entropy $(H)$ - measures the degree of randomness where:

- $H=0$, scattering controlled by a pure or punctual target, in which the signal is fully polarized;

$-0<H<1$, final scattering mechanism results from the combination of three pure targets, and each eigenvector is weighted by the corresponding eigenvalue;

- $H=1$, scattering due to the combination of the three pure targets, indicating the presence of welldistributed targets. 
- Mean alpha angle $(\bar{\alpha})$ - is related to the type of mean scattering mechanism, in which:

$-\bar{\alpha} \rightarrow 0$, surface scattering, Bragg type, producing rough surfaces;

$-\bar{\alpha} \rightarrow 45^{\circ}$, volumetric-type scattering;

$-\bar{\alpha} \rightarrow 90^{\circ}$, double-bounce-type scattering, generated by a dihedral reflector.

- Anisotropy $(A)$ - it complements entropy. It provides information of the relative importance of two of the scattering mechanisms.

Entropy $(H)$ and mean alpha angle $(\bar{\alpha})$ are criteria that permit to characterize the scattering of a medium; thus, they compose a binary diagram that allows classifying the targets into nine randomly divided zones (Fig. 2). Details of this segmentation are given in Cloude \& Pottier (1997).

- Zone 1: high entropy - multiple scattering.

Double-bounce mechanism where $H>0.90$, observed in well-structured surfaces at the sea, like oil platforms and ships;

- Zone 2: high entropy - volume scattering. Volumetric scattering, given by $\bar{\alpha}$, in environment of $H>0.90$, comprising single scattering irradiated froma cloud of acicular anisotropic particles or multiple scattering from a cloud of low loss symmetric particles. This can be produced by some types of surfaces with highly random anisotropic scattering elements;

- Zone 3: high entropy - surface scattering.

This zone is considered not valid because it is impossible to distinguish surface scattering in environment of $H>0.90$;

- Zone 4: medium entropy - multiple scattering. Dihedral scattering in environment of medium entropy, in which the double-bounce mechanism occurs in the $P$ and $L$ bands because of their higher penetration. This zone can also be related to urban areas in the presence of dense scatter arrangements that can generate moderate entropy and low order of dominant multiple scattering;

- Zone 5: medium entropy - volume scattering.

Moderate entropy associated with a predominance of dipole type scattering. The increase of entropy $H$ is due to a central statistical distribution of the orientation angle.
- Zone 6: medium entropy - surface scattering. It reflects entropy increase due to roughness increase because of, for example, effects of wave propagation at the sea surface;

- Zone 7: low entropy - multiple scattering events. Domain of low entropy associated with even bounce and double-bounce mechanisms, such as those generated by isolated dielectric scatters and metallic dihedrons;

- Zone 8: low entropy - dipole modelled scattering. Strong correlated mechanisms occur, which have a large amplitude imbalance between $S_{h h}$ and $S_{v v}$. An isolated dipole scatter could account for this behavior, as well as the scattering could derive from low wind speeds or sea states and no wave breaking.

- Zone 9: low entropy - surface scattering. Modeled by Bragg type surface scattering and specular reflection, which do not involve $180^{\circ}$ phase inversion between $S_{h h}$ and $S_{v v}$.

\section{METHODOLOGY}

The study method was organized in stages. The first stage consisted in the acquisition of previous and relevant information on the subject, through literature review, deepening the knowledge of radar sensor and concepts of polarimetry.

RADARSAT-2 satellite images were selected for the study (Figs. 3 to 6) - obtained in Fine Quad-Pol mode of operation, in the Bay of Campeche, near the Cantarell Complex. Of the four images that were avaiable, two pairs of sequenced acquisition, two with different incidence angle in which the targets aimed were better positioned (Table 1) were chosen. The first, in descending orbit, with spatial resolution of $13.50 \mathrm{~m}$, was acquired on September 20, 2009, in the FQ2W mode of operation, with incidence angle varying in the range from $19.0^{\circ}$ to $22.7^{\circ}$. The second image, ascending, spatial resolution of $8.70 \mathrm{~m}$, from March 1, 2011, FQ15W mode of operation, comprises the range from $33.7^{\circ}$ to $36.7^{\circ}$ of incidence angle.

RADARSAT-2 data preprocessing consisted on the geometric/radiometric correction using the SNAP (Sentinel Application Platform) software, adequate for polarimetric images. After the polarimetric treatment, the raw data was submitted to calibration procedures, multilooking, generation of coherency matrix (T3), Speckle filtering in the Refined Lee mode and $H-A$ - $\alpha$ type decomposition, in that sequence, to improve visual interpretation and obtain information on the target scattering process. 


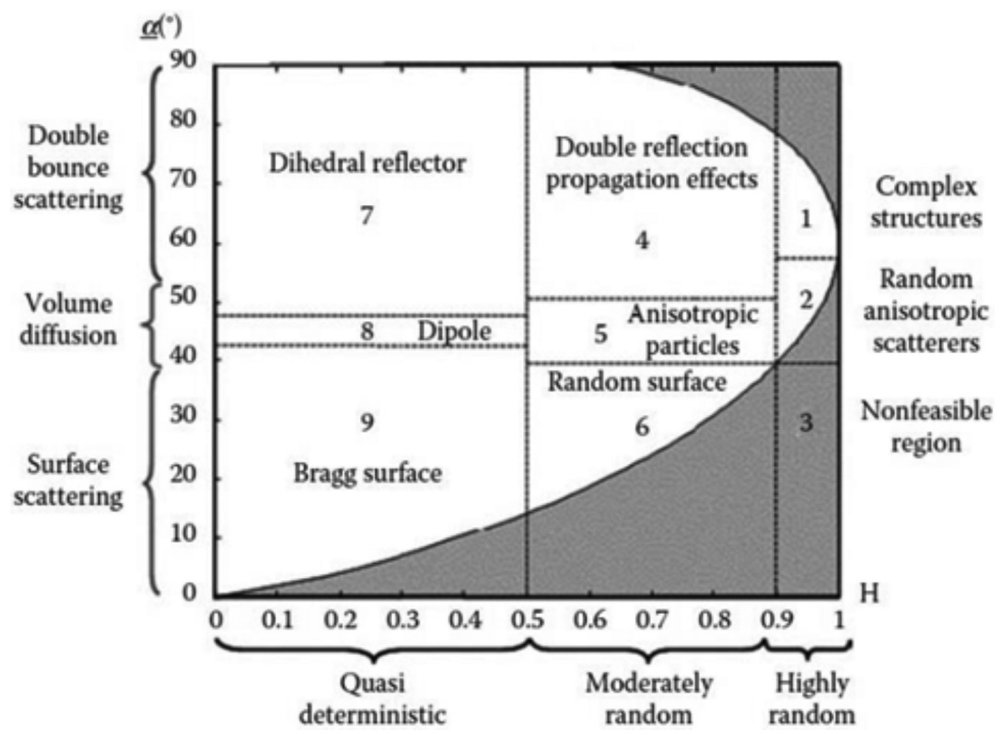

Figure $2-H-\bar{\alpha}$ classification plan with its nine allowable zones (Source: ESA, 2015).

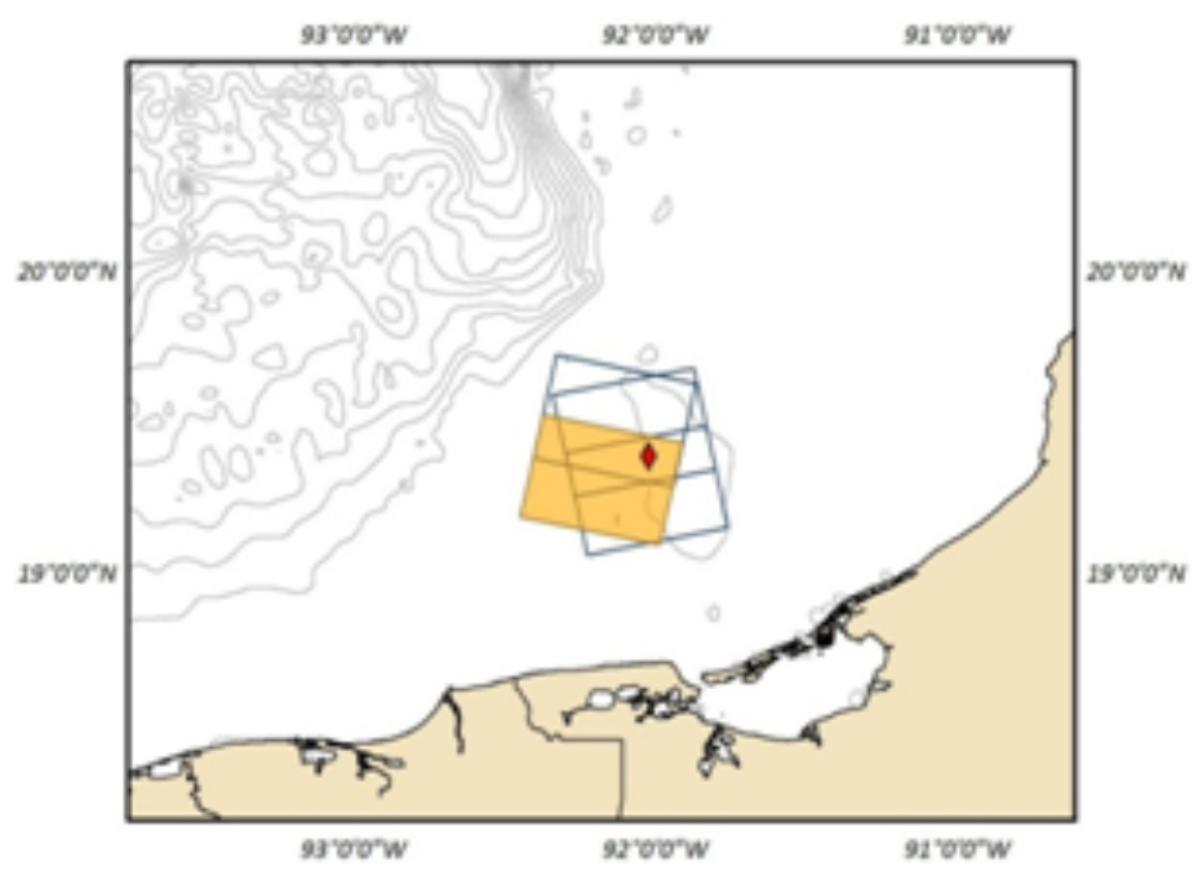

Figure 3 - Location map of RADARSAT-2 satellite polarimetric image ID\#02 (FQ2W acquisition mode). The red lozenge indicates the position of Cantarell oil seep.

The orbital meteo-oceanographic maps available - sea surface temperature (SST), wind field, cloud top temperature (CTT), chlorophyll-a concentration, and significant wave height - were used as support for interpretation (Figs. 7 and 8 ) in an attempt to eliminate false targets, as reported in Miranda et al. (2004).

Georeferenced versions of ID\#02 and ID\#04 were prepared to export them aiming at sample generation, sized $3 \times 3$ pixels, in ArcGIS software, of four targets (oil, platform, sea and false target), in amount enough to obtain the most representative geographic distribution of each class in the images (Table 2). Again in SNAP, the samples from the preprocessing decomposition product, i.e., the coherency matrix (T3) with Speckle removal 


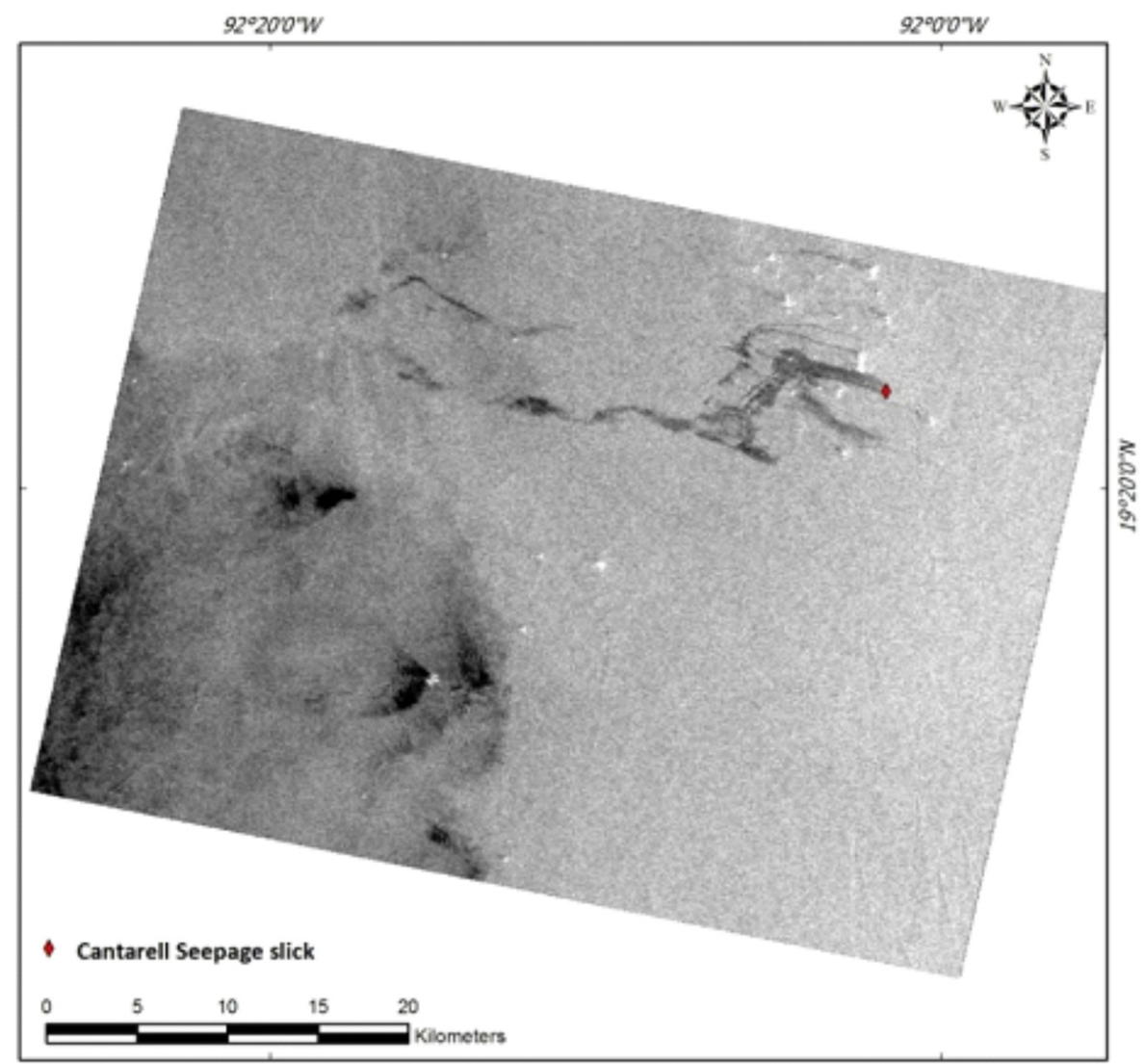

Figure 4 - RADARSAT-2 image with VV type polarization in ID\#02, FQ2W, acquired on September 20, 2009, at 12:11:39 GMT (Source: LabSAR, 2016).

Table 1 - Selected images and location specifications, acquisition mode, spatial resolution, window size, incidence angle, acquisition date and time.

\begin{tabular}{|c|c|c|c|c|c|c|c|}
\hline ID\# & Location & $\begin{array}{c}\text { Acquisition } \\
\text { Mode }\end{array}$ & $\begin{array}{c}\text { Spatial } \\
\text { Resolution } \\
\text { (meters) }\end{array}$ & $\begin{array}{c}\text { Window } \\
\text { Size } \\
(\mathrm{km} \times \mathrm{km})\end{array}$ & $\begin{array}{c}\text { Incidence } \\
\text { Angle Range } \\
\left({ }^{\circ}\right)\end{array}$ & $\begin{array}{c}\text { Date } \\
(\text { month, day, } \\
\text { year })\end{array}$ & $\begin{array}{c}\text { Acquisition } \\
\text { Time } \\
\left({ }^{*}\right)\end{array}$ \\
\hline 02 & Cantarell & FQ2W & 13.50 & $50 \times 25$ & $19.0-22.7$ & Sep 20, 2009 & $12: 11: 39$ \\
\hline 04 & Cantarell & FQ15W & 8.70 & $50 \times 25$ & $33.7-36.7$ & March 1, 2011 & $00: 16: 08$ \\
\hline
\end{tabular}

*GMT - Greenwich Mean Time.

employing Refined Lee filter were analyzed. The samples were imported as masks that allowed obtaining the Cloude \& Pottier diagrams (1997) through a tool of the software itself. Data extraction took place in two moments. First, the values of row, column, incidence angle and backscattering coefficient (shown as a function of intensity $H H, H V, V V$ - converted into $\mathrm{dB}$ ) of the central pixel of the individual samples were acquired.

Then, with the values mentioned in the previous paragraph known, the entropy $(H)$ and alpha angle $(\bar{\alpha})$ were determined, calculated as a mean of the nine pixels $(3 \times 3$ samples). With this data set, a database to visualize the registers in a dynamics manner and combine them into illustrative schemes according to the need for analysis/interpretation was created.

The SAR images, maps and software programs used in the project were acquired or produced by the Laboratory of Radar Remote Sensing applied to the Oil Industry (LabSAR), linked to the Laboratory of Computational Methods in Engineering (LAMCE), of COPPE/UFRJ, that has developed researches on oil seepage 


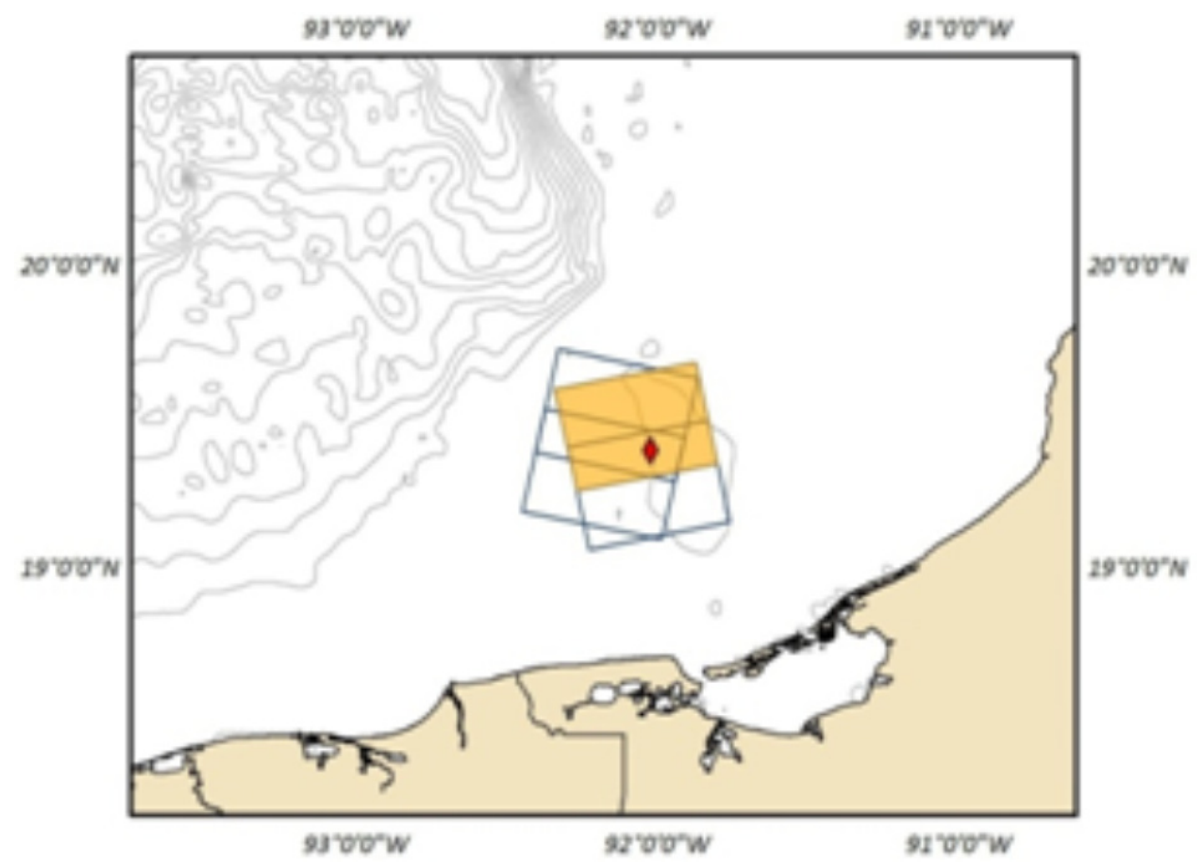

Figure 5 - Location map of RADARSAT-2 satellite polarimetric image ID\#04 (FQ15W acquisition mode). The red lozenge indicates the position of Cantarell oil seep.

Table 2 - Amount of samples collected by class (oil, platform, sea and false target) for each image used.

\begin{tabular}{|c|c|c|c|c|c|c|c|}
\hline ID\# & $\begin{array}{c}\text { Incidence } \\
\text { Angle }\end{array}$ & Class & $\begin{array}{l}\text { No. of } \\
\text { Samples }\end{array}$ & ID\# & $\begin{array}{l}\text { Incidence } \\
\text { Angle }\end{array}$ & Class & $\begin{array}{c}\text { No. of } \\
\text { Samples }\end{array}$ \\
\hline \multirow{4}{*}{02} & \multirow{4}{*}{$19.0^{\circ}-22.7^{\circ}$} & Oil & 200 & \multirow{4}{*}{04} & \multirow{4}{*}{$33.7^{\circ}-36.7^{\circ}$} & 0il & 200 \\
\hline & & Platform & 75 & & & Platform & 75 \\
\hline & & Sea & 75 & & & Sea & 75 \\
\hline & & False Target & 75 & & & False Target ${ }^{\star}$ & $x$ \\
\hline
\end{tabular}

${ }^{*}$ This class is not present in ID\#04 image.

phenomenon in offshore petroleum systems for over ten years (e.g., Carvalho et al., 2016).

\section{RESULTS}

The preparation of the Cloude \& Pottier diagrams (1997), that relate entropy $(H)$ and alpha angle $(\bar{\alpha})$ (Figs. 9 and 10), represents the final stage and that of highest contribution of this study. Differences in sea, platform, oil and false target behavior are noteworthy with regard to the different ranges occupied by the samples' values and to the correspondence for one or more of the nine allowable zones outlined in the mentioned diagrams.

It is through this classification plan that the characterization of the target scattering mechanisms is obtained, since for images covering approximately the same geographic area and with an acquisition time gap, similarly to ID\#02 and ID\#04, disparate responses are observed, that are the object of this discussion.

Figures 11 and 12 show a comparative picture of the data already presented individually, confronting the relevant targets and promoting a general visualization. Such results contribute to the discussion on the influence of imaging geometry on the polarimetric response of the objects.

The variables $H$ and $\bar{\alpha}$ were also statistically characterized, and the mean and standard deviation were determined (Table 3).

\section{DISCUSSION}

The interpretations of the Cloude \& Pottier diagrams (1997) (Figs. 9-12) show heterogeneous responses for the samples from one image to the other, thus, the following aspects can be put 


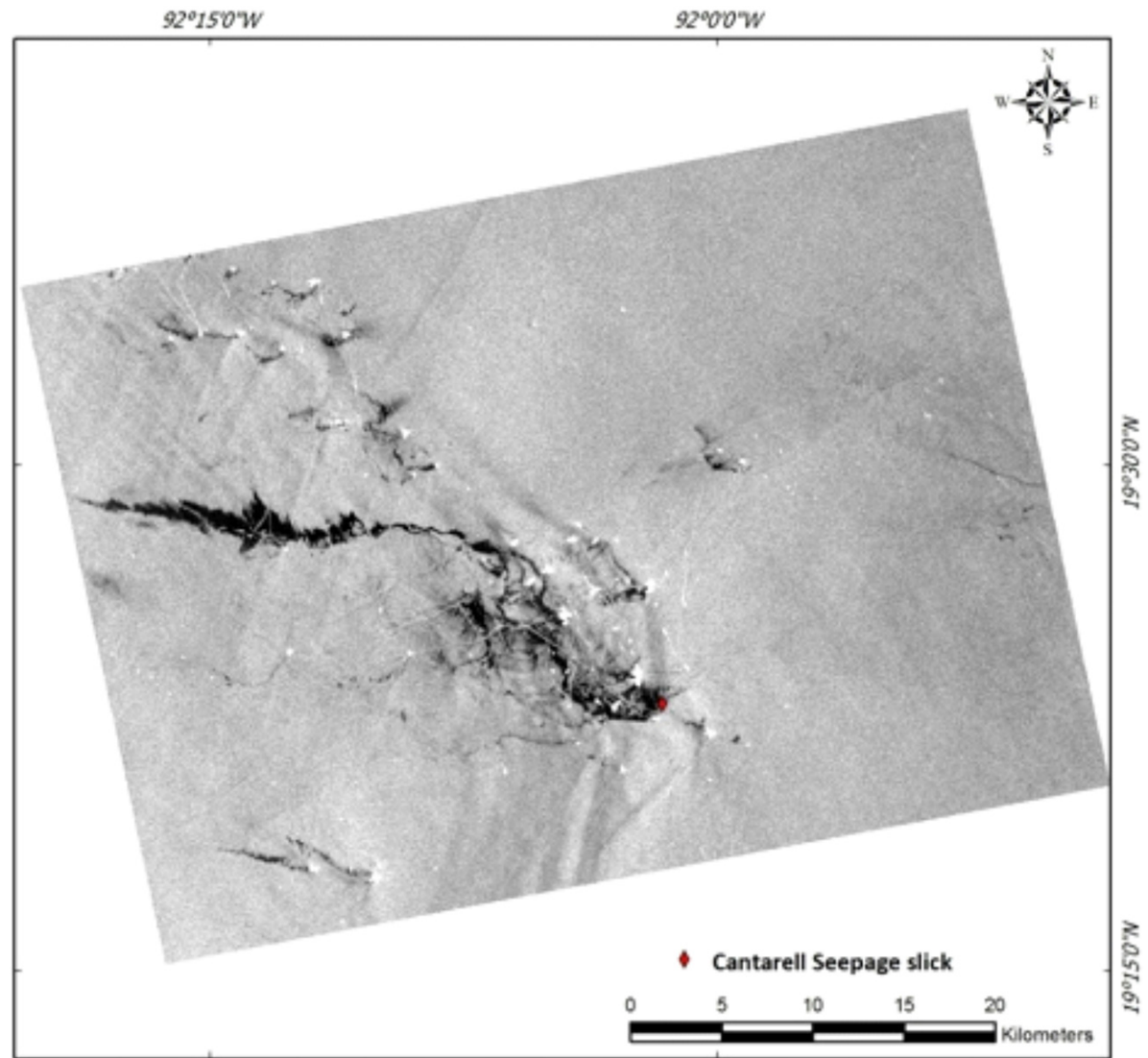

Figure 6 - RADARSAT-2 image with VV type polarization in ID\#04, FQ15W, acquired on March 1, 2011, at 00:16:08 GMT (Source: LabSAR, 2016).

Table 3 - Mean entropy $(H)$ and alpha angle $(\bar{\alpha})$ measures of the targets and their respective standard deviations.

\begin{tabular}{|c|c|c|c|c|c|}
\hline Image & Class & $\bar{H}$ & $S_{H}$ & $\bar{\alpha}\left(^{\circ}\right)$ & $S_{\alpha}$ \\
\hline \multirow{4}{*}{ ID\#02 } & Oil & 0.18897352 & 0.04609508 & 6.53 & 2.06 \\
\cline { 2 - 6 } & Platform & 0.72161024 & 0.11996884 & 34.54 & 10.32 \\
\cline { 2 - 6 } & Sea & 0.10080295 & 0.01710645 & 3.96 & 0.86 \\
\cline { 2 - 6 } & False Target & 0.34103733 & 0.11879855 & 13.26 & 6.12 \\
\hline \multirow{3}{*}{ ID\#04 } & Oil & 0.86893012 & 0.08179045 & 44.37 & 6.70 \\
\cline { 2 - 6 } & Platform & 0.84876591 & 0.07927618 & 56.06 & 7.06 \\
\cline { 2 - 6 } & Sea & 0.38064091 & 0.10032235 & 18.28 & 3.93 \\
\hline
\end{tabular}

forward:

i. The sea, in ID\#02, is clearly a Bragg type surface, Z9 low entropy and small alpha angle -; this is due, in part, to the small imaging incidence angle, with less power to distinguish target roughness.

In ID\#04, there is greater data dispersion (higher standard deviation), but still around the mean, tending to Bragg type surface scattering, Z9. ii. Concerning the platforms, ID\#02 does not provide a good characterization, because the range of incidence angle is not appropriate for observation and the standard deviation of the samples is large. Here, the platforms would compose $\mathbf{Z 5}$ - medium entropy and medium alpha angle - and Z6.

In ID\#04, a more uniform concentration of the samples is observed in the field Z4 - medium entropy and large alpha angle -, where multiple scattering mechanisms 


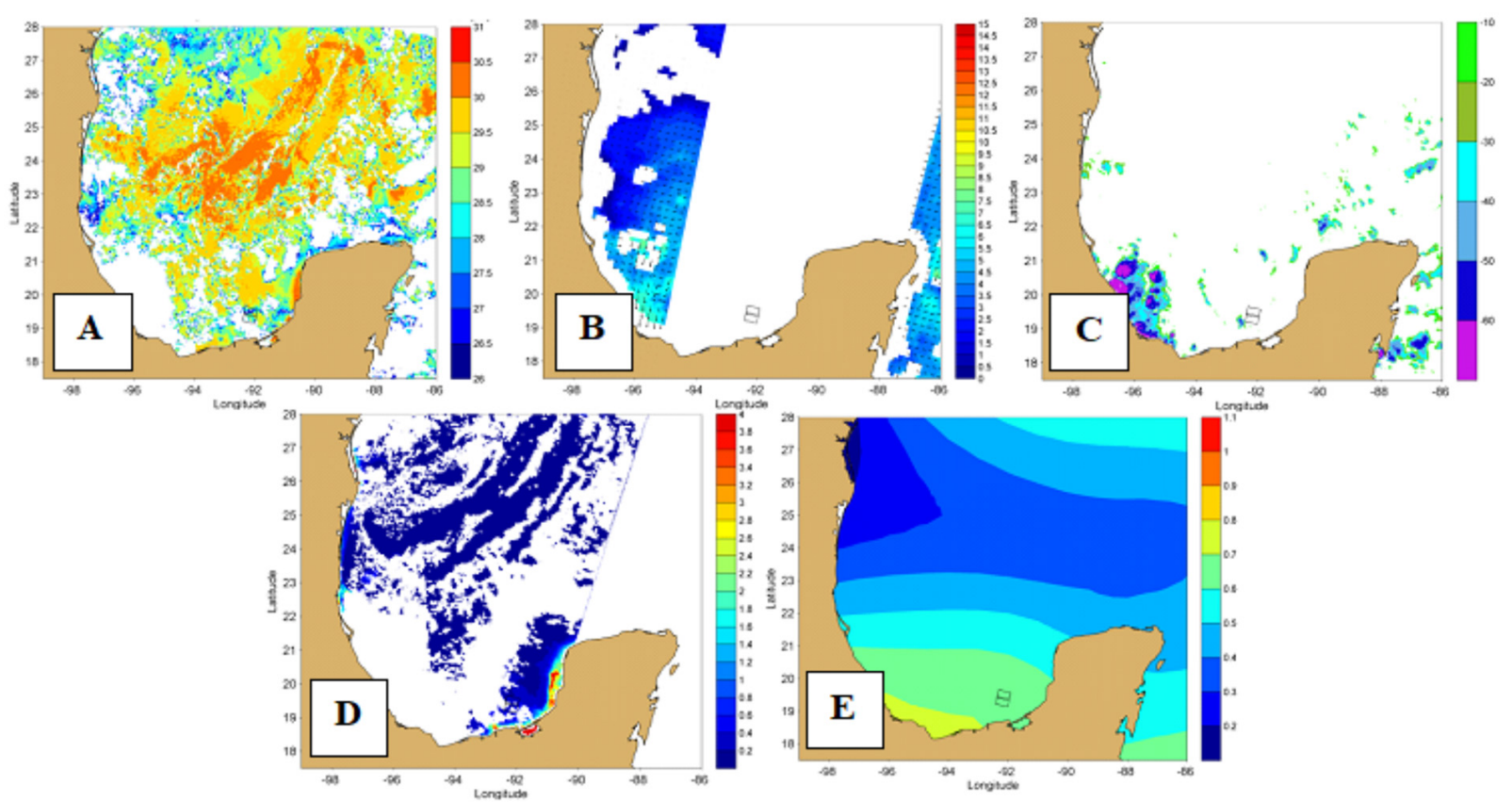

Figure 7 - ID\#02 maps, (A) Sea Surface Temperature (SST) $\left({ }^{\circ} \mathrm{C}\right) ;(B)$ Wind Field (m/s); (C) Cloud Top Temperature (CTT) $\left({ }^{\circ} \mathrm{C}\right) ;(\mathrm{D})$ Chlorophyll-a Concentration $\left(\mathrm{mg} / \mathrm{m}^{3}\right)$ and (E) Significant Wave Height (meters).
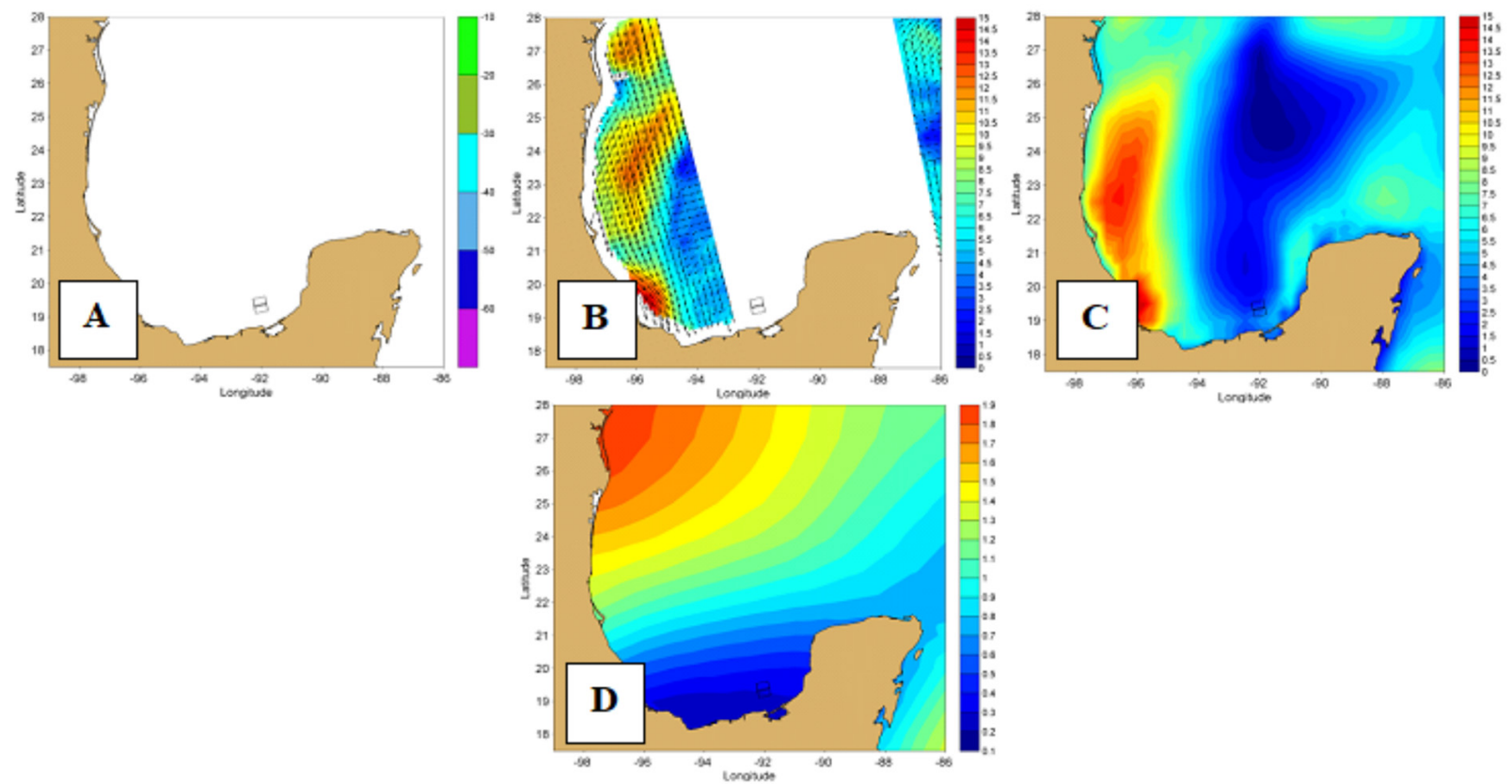

Figure 8 - ID\#04 maps, (A) Cloud Top Temperature (CTT) ( $\left.{ }^{\circ} \mathrm{C}\right)$; (B) Wind Field (m/s); (C) Wind Field in accordance to GFS (m/s); and (D) Significant Wave Height (meters). 

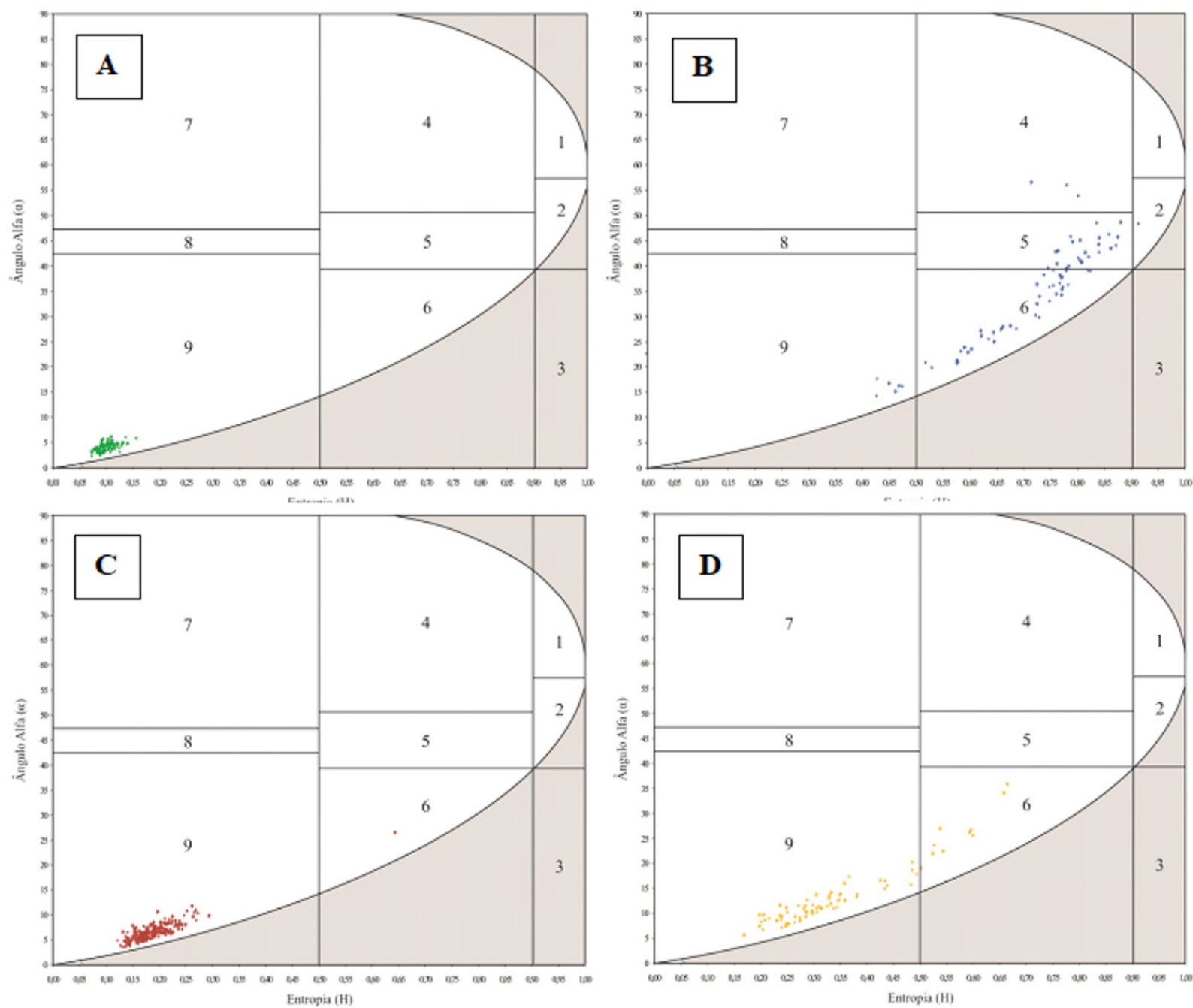

Figure $\mathbf{9}-H-\bar{\alpha}$ diagrams for each target class selected in the ID\#02 image, where $\mathrm{A}=\mathrm{sea}, \mathrm{B}=$ platform, $\mathrm{C}=0 \mathrm{il}, \mathrm{D}=$ false target. The range of the incidence angle is from $19.0^{\circ}$ to $22.7^{\circ}$.

predominate, effects of the propagation of double-bounce reflection.

iii. False targets were only specified in ID\#02; they refer to portions of the image that are misunderstood as oil slick, but, are in fact associated with areas with low wind - speed below $3 \mathrm{~m} / \mathrm{s}$, which cause the attenuation of the energy by the surface, reflecting darker shades of gray. In the $H-\bar{\alpha}$ diagrams, this class can be seen in $Z 9$ and Z6, once the standard deviation is high.

iv. Concerning the oil, it did not affect the Bragg surface in the range $19-22,7^{\circ}$, ID\#02, staying in Z9. The dispersion of the points is noticeably small, but the standard devia- tion calculated does not reflect this behavior, because an outlier, positioned in Z6, which has much higher entropy and higher alpha angle than the rest of the group.

Although it is a surface with a very smooth texture, and that low entropy and small alpha angle are expected, it is plausible to impute part of this response to the small imaging incidence angle.

ID\#04 is quite different from the first image; the oil occupies mostly Z2 - high entropy and medium alpha angle -, Z5 and Z6, and isolated points in Z1 - high entropy and large alpha angle - and Z4. In short, within the range of incidence angle from 33.7 to $36.7^{\circ}$, the randomness is significant. 

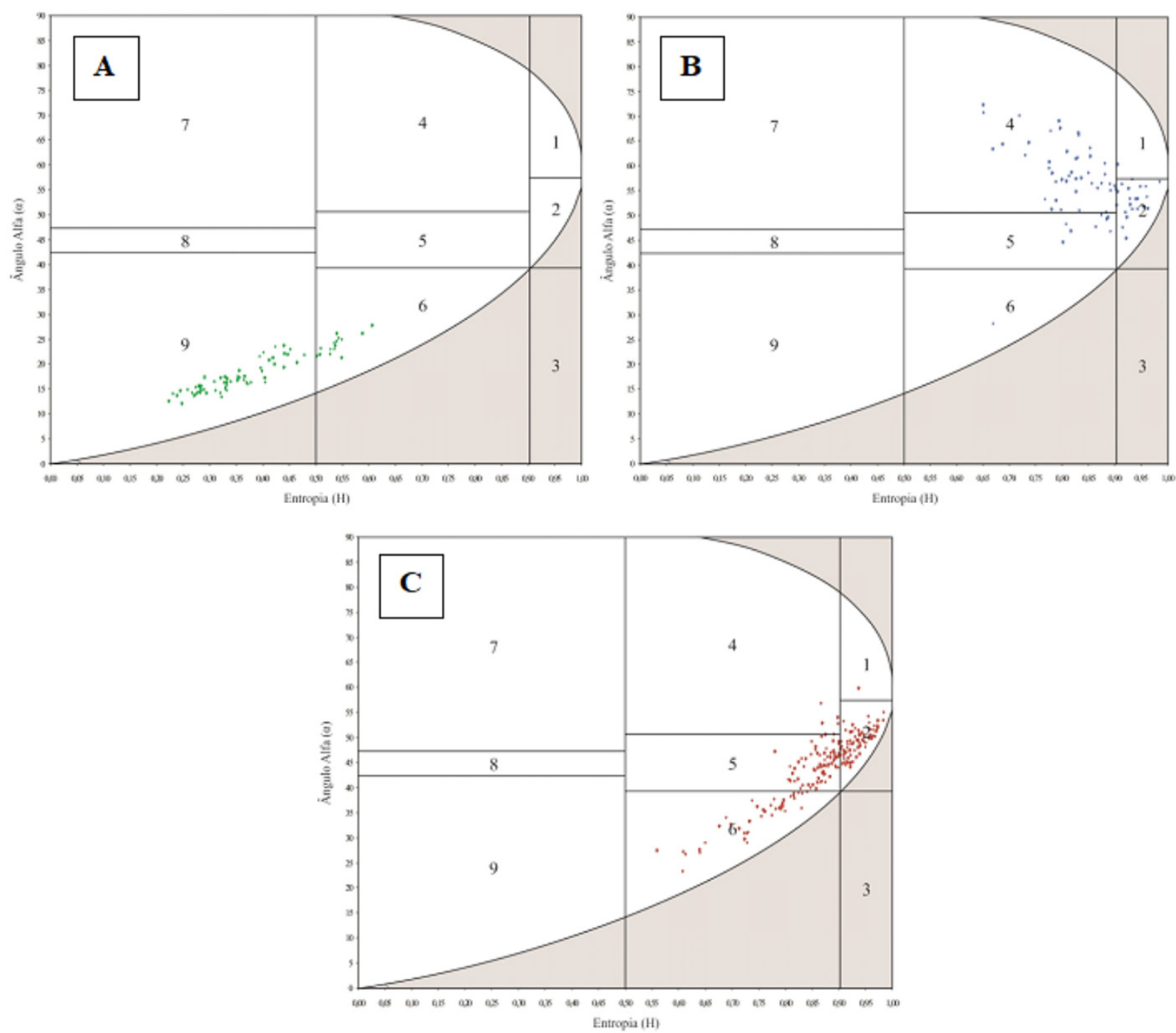

Figure $10-H-\bar{\alpha}$ diagrams for each of the target classes selected in the ID\#04 image, where $A=s e a, B=$ platform, $\mathrm{C}=$ oil. The range of the incidence angle is from $33.7^{\circ}$ to $36.7^{\circ}$.

Table 4 proposes a way to visualize the results reported by some authors of the behavior of oil and sea targets according to the polarimetric characteristics presented by them. The qualitative designations associated to entropy $(H)$ and alpha angle $(\bar{\alpha})$, such as low, medium, high, were mostly established based on the measured numbers available, with the exception of some visual estimates made from the color scale in maps found in the literature. The Zone column of the $H-\bar{\alpha}$ diagram corresponds to an approximation of what would be found graphically, if the reference values of the mentioned authors were plotted, since it is still uncommon to find publications that represent the $H$ - $\bar{\alpha}$ plan as in Figure 2, although the Cloude \& Pottier classification (1997) has been considerably used.
Staples \& Touzi (2014) argue that, for small incidence angles, of less than $30^{\circ}$, sea and oil show similar $H$ values but, as the incidence angle increases, the entropy of the oil increases, while that of the sea remains essentially constant. It is important to highlight that this does not happen when incidence angle and alpha angle are associated.

As can be seen, except for one of the three types of oil described by Tian et al. (2010), all authors follow the relationship above for entropy and incidence angle, including those mentioned in this paper. Although there are no comparative cases for low incidence angles, such as that of ID\#02 imagethe result obtained for ID\#04 image is what was expected, according to the theory and the literature. 


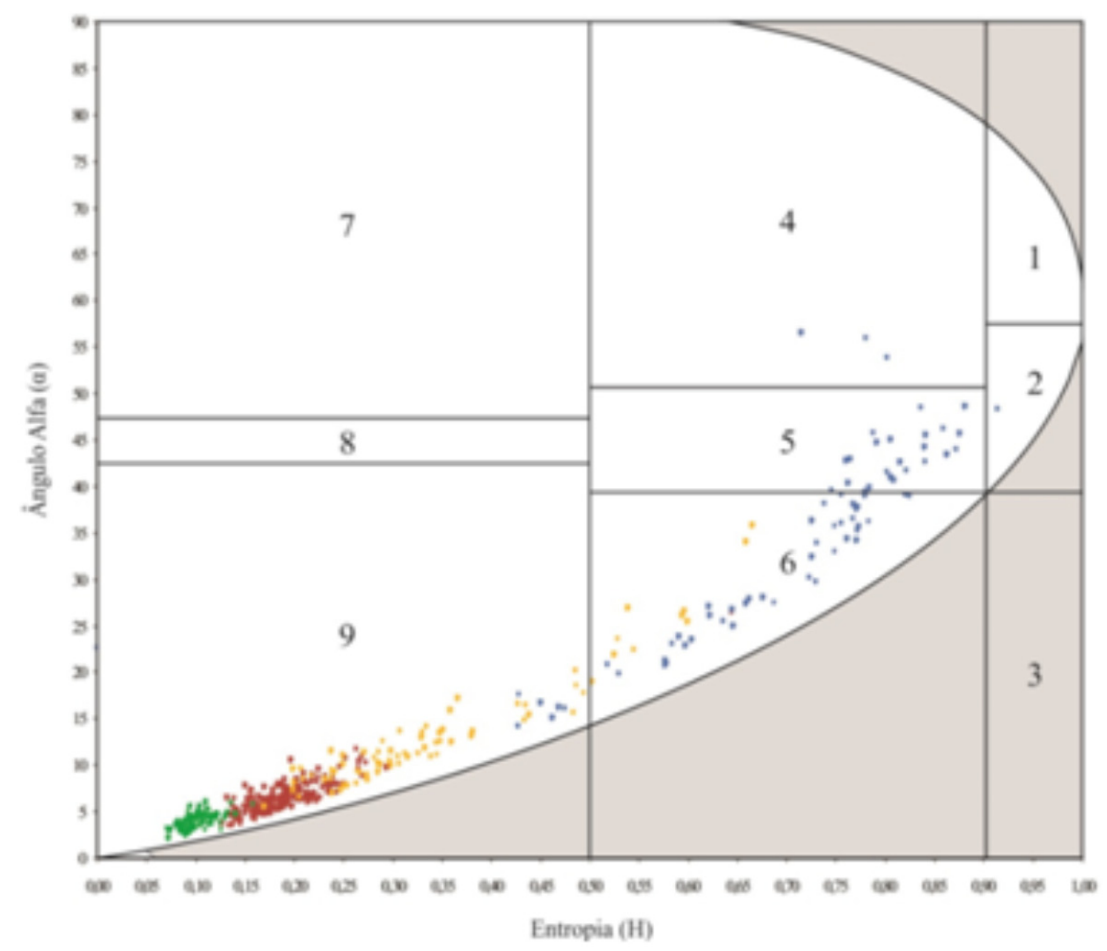

Figure $11-H-\bar{\alpha}$ diagram comparing all targets in ID\#02 image, where green = sea, blue = platform, red = oil, yellow = false target.

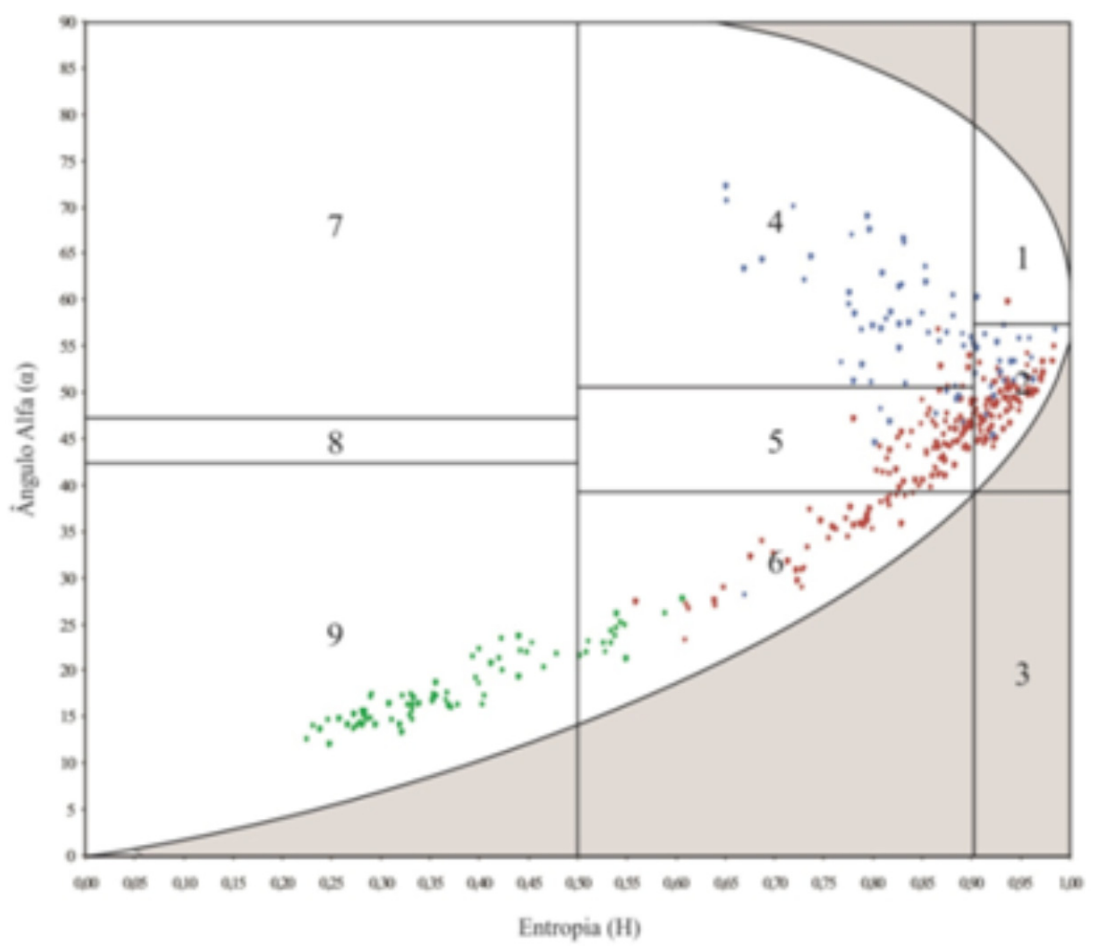

Figure $12-H-\bar{\alpha}$ diagram comparing all targets in ID\#04 image, where green = sea, blue = platform, red = oil. 
Table 4 - Behavior of the sea and oil targets under different incidence angles by different authors according to the polarimetric characteristics $H$ and $\bar{\alpha}$ qualitatively characterized, and the resulting estimated zone of the Cloude \& Pottier classification plan (1997).

\begin{tabular}{|c|c|c|c|c|c|c|c|}
\hline \multirow[b]{2}{*}{ Reference } & \multirow{2}{*}{$\begin{array}{c}\text { Incidence } \\
\text { angle }\end{array}$} & \multicolumn{3}{|c|}{ Sea } & \multicolumn{3}{|c|}{ Oil } \\
\hline & & $H$ & $\bar{\alpha}$ & $\begin{array}{c}\text { Zone of } H-\bar{\alpha} \\
\text { Diagram }\end{array}$ & $H$ & $\bar{\alpha}$ & $\begin{array}{c}\text { Zone of } H-\bar{\alpha} \\
\text { Diagram }\end{array}$ \\
\hline Skrunes et al. (2014) & $46.10^{\circ}-47.30^{\circ}$ & Low & Small & 9 & High & Medium & $5 / 6$ \\
\hline Skrunes et al. (2014) & $34.50^{\circ}-36.10^{\circ}$ & Low & Small & 9 & High & Small & 6 \\
\hline \multirow{3}{*}{ Tian et al. (2010) } & \multirow{3}{*}{$32.55^{\circ}-33.97^{\circ}$} & \multirow{3}{*}{ Low } & \multirow{3}{*}{ Small } & \multirow{3}{*}{9} & Low & Small & 9 \\
\hline & & & & & High & Medium & $5 / 6$ \\
\hline & & & & & Medium & Small & $6 / 9$ \\
\hline Schuler \& Lee (2006) & $23.00^{\circ}-62.00^{\circ}$ & Low & Small & 9 & Low to medium & Low to medium & $6 / 8$ \\
\hline Zhang et al. (2011) & $41.90^{\circ}-43.40^{\circ}$ & Low & Small & 9 & High & Medium & 5 \\
\hline This study & $19.00^{\circ}-22.70^{\circ}$ & Low & Small & 9 & Low & Small & 9 \\
\hline This study & $33.70^{\circ}-36.70^{\circ}$ & Low & Small & 9 & High & Medium & $2 / 5 / 6$ \\
\hline
\end{tabular}

\section{CONCLUSION}

Given four classes of interest (sea, platform, false target and oil), the entropy $(H)$ vS. alpha angle $(\bar{\alpha})$ diagrams of Cloude \& Pottier (1997) and the analysis of the influence of the different imaging incidence angles, the following conclusions in relation to their scattering mechanisms arose:

i. The sea is a Bragg type scattering surface, regardless the incidence angle under which it is observed;

ii. In the platforms, small incidence angles (ID\#02) proved to be inadequate to characterize the polarimetric signature. Larger angles (ID\#04), in turn, are representative of the double-bounce mechanism (although large platform complexes respond in a more random manner);

iii. False targets (regions with little wind), only identified in ID\#02, respond as moderately random/quasi deterministic surfaces of surface scattering;

iv. The oil, for small incidence angles (ID\#02), is similar to the sea, responding with a Bragg type surface. The increase in entropy is concomitant with the increase in incidence angle (ID\#04); alpha angle also increases, but in a less expressive proportion, describing a random and/ or anisotropic surface.

The results presented here, are in accordance with the findings of authors such as Skrunes et al. (2014) and Tian et al. (2010), where the incidence angle and the polarimetric characteristics are similar.

The objective of this study was successfully achieved, contributing to future discussions/researches on the use of SAR polarimetry for characterizing targets in marine environment. It is suggested to assess other polarimetric classification techniques based on target scattering mechanisms, among them Freeman \& Durden (1998) and Van Zyl (1989), as well as approaches associated with compact polarimetry.

\section{ACKNOWLEDGEMENTS}

To COPPE, for the history of scientific encouragement through different academic Master's and Doctor's degree programs and faculty; to LabSAR because of the structure, team, software programs and data made available; and to CNPq for providing the scholarship that allowed full-time dedication to the activities of this project.

\section{REFERENCES}

CARVALHO GA, MINNETT PJ, MIRANDA FP, LANDAU L, MOREIRA F \& BEISL CH. 2016. The Use of a RADARSAT-derived Long-term Dataset to Investigate the Sea Surface Expressions of Human-related Oil spills and Naturally Occurring Oil Seeps in Campeche Bay, Gulf of Mexico. Canadian Journal of Remote Sensing [ISSN 1712-798X], 42(3): 307-321.

CLOUDE SR \& POTTIER E. 1997. An Entropy Based Classification Scheme for Land Applications of Polarimetric SAR. IEEE Transactions on Geoscience and Remote Sensing, 35(1): 68-78.

CNH - Comisión Nacional de Hidrocarburos. 2013. Dictamen Técnico del Proyecto de Explotación Cantarell (Modificación Sustantiva). SENER, Secretaría de Energía, Estados Unidos Mexicanos (July).

ESA - European Space Agency. 2015. SENTINEL-1 Toolbox (S1TBX) Polarimetric Tutorial. (March). Available on: <https://sentinel.esa.int/ web/sentinel/toolboxes > . Access on: August 28, 2017. 
FLORES IBARRA K, MATA CASTILLO C \& NÁPOLES VALENZUELA Jl. 2013. Sonda de Campeche. Available on: < http://es.slideshare.net/ ivannapoles1/sonda-de-campeche>. Access on: August 28, 2017.

FREEMAN A \& DURDEN SLA. 1998. A Three-Component Scattering Model for Polarimetric SAR Data. IEEE Transactions on Geoscience and Remote Sensing, 36(3): 963-973.

IBARRA RM. 2009. Dolomitización y generación de porosidad vugular en la brecha K/T del Campo Cantarell, Zona Marina - Campeche. PhD Thesis, Universidad Nacional Autonoma de Mexico.

IEA - International Energy Agency. 2015. Key World Energy Statistics. France, $77 \mathrm{pp}$.

LabSAR - Laboratório de Sensoriamento Remoto por Radar Aplicado à Indústria do Petróleo. 2016. 3rd Final Report. Novas Tecnologias para o Sensoriamento Remoto de Exsudações de Óleo na Superfície Marinha, UFRJ, Brazil.

LEE SE \& POTTIER E. 2009. Polarimetric radar imaging: from basics to applications. CRC Press: Taylor \& Francis Group, 398 pp.

MIGLIACCIO M, NUNZIATA F, BROWN CE, HOLT B, LI X, PICHEL W \& SHIMADA M. 2012. Polarimetric Synthetic Aperture Radar utilized to Track Oil Spills. Eos, 93(16): 161-163.

MIRANDA FP, MARMÓL AMQ, PEDROSO EC, BEISL CH, MEDRANO L \& WELGAN P. 2004. Analysis of RADARSAT-1 data for offshore monitoring activities in the Cantarell Complex, Gulf of Mexico, using the unsupervised semivariogram textural classifier (USTC). Canadian Journal of Remote Sensing, 30: 424-436.

PEMEX - Petróleos Mexicanos. 2005. Boletines de Prensa. Precisiones respecto al comportamiento del complejo Cantarell. Available on: <http://web.archive.org/web/20070629162437/http://www.pemex. com/index.cfm?action=content \&sectionID=8\&catID=40\&subcatID =3672>. Access on: August 28, 2017.

POWER ENGINEERING. 2015. Mexico sets 25\% pollution cut by 2030 for climate talks. 03/30/2015. Available on: <http://www.powereng.com/articles/2015/03/mexico-sets-25-pollution-cut-by-2030-forclimate-talks.html>. Access on: September 3, 2017.

SCHULER DL \& LEE JS. 2006. Mapping ocean surface features using biogenic slick-fields and SAR polarimetric decomposition techniques. IEE Proceedings - Radar, Sonar and Navigation, 153(3): 260-270.

SKRUNES S, BREKKE C \& ELTOFT T. 2014. Characterization of Marine Surface Slicks by Radarsat-2 Multipolarization Features. IEEE Transactions on Geoscience and Remote Sensing, 52(9): 5302-5319.

STAPLES G \& TOUZI R. 2014. The Application of RADARSAT-2 QuadPolarized Data for Oil Slick Characterization. In: International Oil Spill Conference, Savannah, Georgia, pp. 2242-2252.

TIAN W, SHAO Y, YUAN J, WANG S \& LIU Y. 2010. An Experiment for Oil Spill Recognition using RADARSAT-2 Image. In: Proceedings of International Geoscience and Remote Sensing Symposium (IGARSS), Honolulu, Hawaii, USA, pp. 2761-2764.

VAN ZYL JJ. 1989. Unsupervised classification of scattering mechanisms using radar polarimetry data. IEEE Trans. Geosci. Remote Sens., 27: $36-45$.

ZHANG B, PERRIE W, LI X \& PICHEL WG. 2011. Mapping sea surface oil slicks using RADARSAT-2 quad-polarization SAR image. Geophysical Research Letters, 38: L10602. 